\title{
Modern Teacher's Worldview and Ethics in the Context of Technological Paradigms (Case Study of a National Region of Russia)
}

\author{
A.D. Nikolaeva ${ }^{1, *}$, S.A. Filin ${ }^{2}$, and D. Davaasurengiyn ${ }^{3}$ \\ *Corresponding author: allanikol@list.ru. \\ ${ }^{1}$ Ammosov North-Eastern Federal University, Pedagogy Chair, Yakutsk, Russia \\ ${ }^{2}$ Plehanov Russian Economics University, Moscow, Russia \\ ${ }^{2}$ Mongolia State University of Culture and Arts, Science and Innovation Chair, Ulaanbaatar, Mongolia
}

\begin{abstract}
The authors discuss the process of formation of worldview and ethics among modern teachers in the context of establishment of a new system of values due to changing technological paradigms. Based on historical-pedagogic and moral values, which are the foundation of pedagogic education, prospects for the development of worldview ethics of future teachers have been identified in the context of changing technological paradigms. The authors emphasize the influence on the worldview and ethics of teachers of, on the one hand, natural-climatic factors, connected with the implementation of ethno-pedagogic origins of education, and, on the other hand, scientific-technical revolution, connected with intensive economic innovative development processes. The significance of environmental awareness in forming new ethical outlooks, connected with the understanding of existing environmental issues, is confirmed by empirical evidence.
\end{abstract}

Keywords: teacher, environmental awareness, ethics, innovative worldview, technological paradigm, educational space.

\section{Introduction}

The relevance and originality of the research topic is attributed to the idea that the processes of globalization, ongoing in the world and affecting various spheres of life in society, are characterized by accelerated changes in the existing ways of life, establishment of a new system of values and re-evaluation of the global goals of human existence. In this context, the highest significance is gained by the role of a teacher, as an instrumental influence in forming the personalities, way of life and innovative worldview, consciousness and mentality of students. The diversity of naturalgeographic, climatic, ethnic, demographic, sociocultural, educational and other features of Russian regions, including the national region of the Sakha Republic (Yakutia), brings about the need for multicultural cooperation in order to, among other things, form individual personal qualities and personalities in general. A special role in modern conditions of societal development is played by the influence of worldview and ethics of a contemporary teacher in the upbringing of young students.

\section{Methods}

The methodological framework of the research is based on the concept of interrelation and interdependence of social, culturological, pedagogical, objective and subjective factors in the development of pedagogical education on the foundation of interdisciplinary connections: economics, philosophy, culturology, pedagogics. To reach the goals of our research a number of theoretical methods were used, based on the requirements of expert-analytics work: reflective analysis of literature on philosophy, economics, psychology and pedagogics; methods of theoretical analysis, synthesis of pedagogical approaches, comparison, classification, systematization, surveys, observation, questionnaires.

\section{Results}

N.U. Yarychev [1] identifies two levels of socio-cultural environment: "macro-environment (economic conditions, social relations, culture of society)" and "microenvironment" (family, friends, specific organizations, homes, specific natural landscape)", which are constantly interacting and influencing each other. As the ethics and worldview of a teacher are influenced by socio-cultural and ecological environments, the diversity of training models of modern teachers, including in national regions of Russia, has unique socio-cultural, ecological and other features. Each nationality combines both universal human traditions and original features in forming the culture of teachers, which are all organically integrated into the single socio-cultural standard of forming the personality and professional qualities of Russian teachers. The evolution of ethics and worldview of a personality in Russia, including in Yakutia, "as a leading socio-cultural activity, has largely been a historic process of developing ethno-cultural education and its influence on personalities" [2]. According to U.S. Borisova [3], during the process of ethno-cultural education future teachers 
assimilate ethno-cultural values: language, culture, historic and spiritual heritage. Correspondingly, the foundation for the evolution of worldview ethics of a teacher is the preservation and reproduction of spiritual traditions of peoples and folk pedagogic. This has been a long process of evolution of ethno-pedagogical education, starting from the first schools of Kievan Rus, through the school education reforms of the $17^{\text {th }}-19^{\text {th }}$ centuries, to the revival and development on the cusp of the $20^{\text {th }}$ and $21^{\text {st }}$ centuries.

Principal factors that influenced the formation and evolution of folk pedagogic were the natural-climatic environment and factors connected with the implementation of ethno-pedagogical origins of upbringing. Analysis showed that in thousands of years specific means of regulating the relations of people and the environment have formed in Russia and Yakutia during the process of societal and natural evolution: natural-geographic conditions in Yakutia are closely connected with traditional economies and affect the development of peoples and formation of their ethical values and general worldview. The richness of traditions and experience of folk pedagogic "contributed to the development of a worldview ethics of teachers" [4]. Thus, the specific feature of the evolution of worldview ethics of teachers in Yakutia is the fact that its formation has been influenced by various conflicting factors, due to which the qualitative changes that took place during this process have significant scientific, historic and practical value for modern pedagogy.

The analysis of worldview of modern teachers in the context of establishment of a new system of values during shifting technological paradigms (TP) shows that it is influenced by many modern processes, in particular, the everincreasing demand of humanity for energy, primarily in economically developed countries, due to which there are significant changes in the natural-geographic and climatic conditions of Russian regions: thawing of permafrost, melting of ice sheets in the Arctic part of the country, warmer and shorter winters, increasing mean annual air temperatures in Russia and the world. The number and intensity of natural cataclysms is rising, and the environment is worsening. Shifting TPs inevitably lead to changes in the system of values of social groups and societies in general, as well as adaptation of people to shifting TPs due to the fact that it is human capital which is the driving force behind the economic development of countries. Without characterizing all the TPs we would like to point out that in conditions of the sixth TP (1985-2035) (digitalization of economy, homestead urbanization of a "cloth" type, new medicine, new types of communication) enhanced capabilities are expected from organizations and people, as well as investment into them, planning of future and its management, resolution of problems within the frames of coevolution, presence of a new level of education system, artificial intelligence, high humanities and environmental technologies (new environmental management), and technologies of assembly and destruction of social subjects. The potential for development of this paradigm allows us to expect by the year 2020 radical changes in economic and social spheres: improvements in the quality of life and life expectancy, changes in the character of labour. Convergence of nano-, bio-, cognitive and information and communication technologies that form the sixth TP [5] is oriented towards cognitive processes. This is cognitive science that provides for new rationality and vision of the world. However, if by 2040 the humanity does not fully transition to the sixth TP, new global issues are unavoidable, connected with the provision of energy and resources, which can lead to a severe global crisis [6, p. 21].

The analysis of worldview of modern teachers in the context of establishment of a new system of values during shifting TPs shows that at present there are two principal global trends that have the highest chance in influencing the direction of development of pedagogical school, people and human civilization in general: 1 . humanity is concerned with issues connected with the shrinking and coorganization of sociohumanitarian and socio-cultural diversity due to globalization processes; 2 . humanity is carrying over to the future the determinant of the environment: the crisis in the organization of life of humanity in general, which for the most part causes financial-economic and other types of crises, due to which humanity will be actively searching for ways of organizing its life in the future and for new ways of using intellectual capital.

At present, Russia is systematically introducing new sociohumanitarian technologies on a large scale, which can improve quality of life. This is why there are opportunities in the country to develop and effectively use sociohumanitarian and socio-cultural technologies with a positive synergetic effect in order to accelerate its innovative development based on original traditions and ways of thinking in these spheres, as well as intellectual, creative and scientific capacity of the population and the involvement of Russians in innovative activities. According to O. Bakhtiyarov [7] "the source of human activity is shifting from external (social, cultural, enforced) stimulation to internal consciousness, to active, strong-willed, creative layers." This signifies a change in the concept of a human and another project to create a new human, oriented towards technologies, the basic characteristic of whom will be the ability to generate new socio-cultural and technological realities and the possibility of "coding" it. Possible programming of a part of human thinking, when it will stop being a purely biological phenomenon, and the human brain will become an analogue of a hard drive, will increase human efficiency: if some knowledge is forgotten or disappears with a human, it will be possible to restore it by downloading the relevant information. That is, capabilities of human memory will be expanded. Thus, the worldview of a teacher is influenced by natural-climatic environment and factors connected with the implementation of ethno-pedagogical origins of education on one hand, and the scientific-technological revolution and connected processes of intensive economic innovative development on the other [8]. Russian and foreign researchers agree that in modern conditions environmental ethics as the foundation of environmental awareness becomes extremely relevant, forming ethical-environmental views in every region of Russia: "the topic of ecology and environmental ethics is firmly ingrained in the social consciousness. The fragility and vulnerability of nature in the Russian North, the delicate nature of the balance of the "human - nature society" system are now fundamental truths in social consciousness" [9-11]. Environmental awareness is crucial in forming new ethical values connected with the understanding of existing environmental issues, rational and careful attitude towards nature and the environment, new ways of developing the world, information civilization, actualization of the 
creative potential of a personality, complex understanding of the modern world image, consolidation of social activities and establishment of various social environmental movements and, correspondingly, new (innovative) type of worldview [12-14]. The above point is confirmed by the results of a survey held by the authors among the teachers and students of Russian universities (sampling): environmental issues have been shown as significant by $100 \%$ of respondents, including the issues of air quality, drinking water, safety of food products, declining health of population etc. Global climate change was a point of major concern, signifying the spread of environmental awareness and the level of environmental education. Russian students answered that the main factor in formation of ethical culture is the protection of the environment and its influence on the formation of worldview ethics (84\%). Most respondents (teachers and postgraduate students - future teachers selected in the sampling) include among the factors that influence the worldview ethics of modern teachers such points as the evolution of society, state and political system of a country, the level of moral and cultural development of society, historic and cultural features, natural and socio-cultural environment, development of science and education. 82.9\% of the Ammosov North-Eastern Federal University students responded favourably to the preservation of traditional, national way of life, reasoning that this will preserve a unique civilization living in harmony with nature. Teachers pointed out that the system of conditions and activities for forming ethics and worldview of a modern teacher can be based on the integration of personality-oriented, competence, culturological and axiological approaches, the foundation for which is the modelling of results of education in university on the basis of forming a value-worldview culture of personalities of future teachers [15]; orientation towards the motives and goals of a teacher's personality; translation of societal values onto the personality and education process, including the values formed by the modern scientific-technological revolution and connected processes of intensive innovative development etc.

Questioning students on the ethical worldview of future teachers also showed the indisputable influence of family $(38 \%)$, mass media $(27.6 \%)$ and educational institutions (schools $-16.2 \%$, university $-10.1 \%$ ) that comprise the sociocultural environment, which builds pedagogical activity that recreates in teachers ethical, worldview and ethno-cultural values. The leading aspect that actualizes the significance of worldview and ethics of the younger generation for social development is that based on their ethical and worldview understanding young people define for themselves which directions of development are progressive at the current point of time and which are not. Additionally, under the influence of professional activities of teachers, the cultural-educational environment of an educational institution can change, and subsequently, under that influence, the socio-cultural environment can change in the educational institution at first, and then, possibly, in the society at a corresponding level. While studying the evolution of socio-cultural educational environment in the context of historical stages of societal development, closely connected with traditional economies, specific means of regulating relations of people and nature, as well as the diversity of cultural-labour and spiritual-moral orientations and traditions, we found that this environment forms ethical views of modern humans, including teachers: in the aspects of establishment of a new system of values, formation and development of ethical views of a teacher both in the educational process and the open environment of a university (school), the bearers or subjects of which are teachers as personalities and systems, theories and technologies of education and pedagogical upbringing introduced by them; in the socio-cultural aspect of forming an innovative worldview, consciousness and way of thinking of young people as personalities (politics, culture, creativity, traditions, family, education, socially useful work, sport, health etc); in the "human - society - nature" system (civic activities, self-organization, positive or negative synergetic effect depending on the person's attitude towards nature, society, own life). Russian questionnaire participants place equal emphasis on such social phenomena that affect the formation of a personality as understanding of the value of nature (40.1\%), attitude towards political and social life of a country and participation in it (47.4\%), considering the traditional way of life as a unique civilization $(82.9 \%)$.

\section{Conclusion}

From the point of view of establishment of a new system of values in the context of shifting technological paradigms, the worldview of a modern teacher is characterized by its relation to the teacher's attitude towards nature, society, different facets of the environment, self and own life, which is expressed in convictions, beliefs, ideals, values that characterize the spiritual-moral sphere of the teacher's personality, direction of worldview, consciousness and way of thinking. Formation of innovative worldview, consciousness and way of thinking of a teacher is largely determined by, on the one hand, understanding of the priority of environmental awareness that projects ethical views connected with the recognition of existing environmental issues, rational and gentle attitude towards the environment, and, on the other hand, scientific-technological revolution and connected processes of intensive development of innovative production activities that result in a digital economy that promotes the actualization of a creative potential of a personality, complex understanding of the modern world image and, subsequently, establishment of this type of worldview. Socio-cultural environment and open socio-cultural educational space are factors that define the regional features of historic and modern educational practices, significantly influencing pedagogical processes and ethics formation, innovative worldview, consciousness and way of thinking of both teachers and, under their professional influence, socio-cultural environment in an educational institution and society at the corresponding level. Beliefs and convictions of teachers transform into motives that compel them to change and develop their moral worlds that affect through pedagogical upbringing and educational process the formation of ethics and innovative worldview, consciousness and way of thinking of students, who are the future human capital of innovative economies in new technological paradigms. 


\section{Acknowledgements} 03003 .

The article was written with the financial support of the Russian Foundation for Basic Research, Project \#17-26-

\section{References}

1. N.U. Yarychev, The concept of developing conflict resolution culture of a teacher in a self-educating organization. Ph.D. thesis. Chelyabinsk: Chelyabinsk Institute of Retraining and Continuing Education of Educators (2011). [in Rus.].

2. A.D. Nikolaeva, S.A. Filin, D. Davaasurengiyn, Origins of the formation of the world outlook ethics of the teacher in Russia (on the example of the national region of the Republic of Sakha (Yakutia). Discussion, 7, 90-95 (2017). [in Rus.].

3. U.S. Borisova, Ethnocultural education: Historical-sociological analysis: A case study of the Sakha Republic (Yakutia.). Ph.D. thesis. St. Petersburg: St. Petersburg University (2006). [in Rus.].

4. A.D. Nikolaeva, O.P. Osipova, The formation of ethics and world outlook of the future teacher. In V. Chernyavskaya, H. Kuße (Eds.), Proceedings of the 18th PCSF 2018 - Professional Culture of the Specialist of the Future. The European Proceedings of Social \& Behavioural Sciences EpSBS, 51 (pp. 615-662). London: Future Academy (2018). DOI: 10.15405/epsbs.2018.12.02.67.

5. Yu.V. Yakovets, Landmark innovations of the $21^{\text {st }}$ century (Ekonomika, Moscow, 2004). [in Rus.].

6. I.A. Shumpeter, Theory of economic development. Capitalism, socialism, democracy (Eksmo, Moscow, 2007). [in Rus.].

7. O. Bahtiyarov, People of new willpower: Social-humanitarian paradigm and its creators. Development and Economics, 3, 150-163 (2012). [in Rus.].

8. A.Zh. Yakushev, Formation of innovative consciousness as one of the key aspects of ensuring the innovative scenario of economic development. Science Journal of Volgograd State University. Global Economic System, 4(33), 150-160 (2015). [in Rus.].

9. F.M. Giorgett, C. Campbell, A. Arslan, Culture and education: Looking back to culture through education. Pedagogica Historica, 53(1-2), 1-6 (2017).

10. A.D. Nikolaeva, V.M. Savvinov, Multi-ethnic school in the Russian Federation: The preconditions of formation and development (a case study of a national region). International Electronic Journal of Mathematics Education, 11(10) (2016).

11. H. Ivon, D. Kuscevic, School and the cultural-heritage environment: Pedagogical, creative and artistic aspects. Center for Educational Policy Studies Journal, 3(2), 29-50 (2013).

12. Z. Komar, Free time as time of true education. Filozofska istraživanja, 2(114), 297-302 (2009).

13. N.D. Neustroev, A.D. Nikolaeva, A.N. Neustroeva, A.V. Ivanova, Problems and modernization trends of ungraded schools of the Russian North. International Electronic Journal of Mathematics Education, 11(10) (2016).

14. F. Trede, Role of work-integrated learning in developing professionalism and professional identity. Asia-Pacific Journal of Cooperative Education, 13(3), 159-167 (2012).

15. S.A. Filin, A.D. Nikolaeva, A.Z. Yakushev, I.S. Alexeeva, Training of specialists for "digital" and innovative economies. In V. Chernyavskaya, H. Kuße (Eds.), Proceedings of the 18th PCSF 2018 - Professional Culture of the Specialist of the Future. The European Proceedings of Social \& Behavioural Sciences EpSBS, 51 (pp. 680-688). London: Future Academy (2018). DOI: 10.15405/epsbs.2018.12.02.74. 